\title{
Status and distribution changes of the endangered Green Peafowl (Pavo muticus) in China over the past three decades (1990s-2017)
}

Dejun Kong ${ }^{1}$, Fei Wu ${ }^{2}$, Pengfei Shan ${ }^{2}$, Jianyun $\mathrm{Gao}^{2}$, Dao Yan² ${ }^{2}$ Weixiong Luo ${ }^{3}$ and Xiaojun Yang ${ }^{2 *}$

\begin{abstract}
Background: Understanding the changes in population dynamics, including demographics, distribution and threats, is essential for species status assessing. The endangered Green Peafowl (Pavo muticus) has experienced sharp population declines and distribution range diminishing both in China and Southeast Asia. Field population surveys have not been conducted in China since the 1990s, which hindered conservation planning and decision-making.

Methods: With interview and line transects methods, we figured out the population and distribution changes of Green Peafowl across its historical ranges over the past three decades in China during 2014-2017.

Results: The Green Peafowl once habituated in 54 counties in China. Nearly $60 \%$ of the distribution counties were lost in the past three decades, with the left 22 counties distributed in central, southern and western Yunnan, SW China. Population decrease detected in all distribution areas except for Shuangbai and Xinping county where more than $60 \%$ of the total population is located. Only about $30 \%$ of the former bird population were recorded with the same interviewing method as 20 years ago. Three birds, 1 carcass, 6 calls and 12 footprints were detected along the $865 \mathrm{~km}$ line transects, indicating extremely low encounter rate of Green Peafowl in field. Sharp decreases in flock sizes were also detected, from 8-20 birds per flock in the 1990s to 3-5 birds at present. Poaching and habitat conversion are two widespread and long-lasting threats, while poisoning caused mortality in the past and hydropower construction affect regional population's survival. Large flocks of 18-27 birds were discovered in the field, which increases our confidence of population recovery of this endangered pheasant in China.
\end{abstract}

Conclusions: Only interviewed bird number and counts based on line transects were presented in this study, without further population estimation due to limitation of the data sets. Although the actual population of this cryptic bird must be underestimated, dramatic population declines and distribution concentrations of the endangered Green Peafowl occurred over the past 30 years in China undoubtedly.

Keywords: Green Peafowl, Population decline, Range concentration, Endangered species, Southwestern China

\footnotetext{
*Correspondence: yangxj@mail.kiz.ac.cn

2 Bird Group, Kunming Institute of Zoology, Chinese Academy of Sciences,

Kunming 650223, China

Full list of author information is available at the end of the article
} 


\section{Background}

The Green Peafowl (Pavo muticus) is one of the most threatened pheasants in the world. As a typical grounddwelling pheasant species, the Green Peafowl is native to the tropical and subtropical forests of Southeast Asia from Java, to Thailand, Cambodia, Laos, Vietnam, Myanmar, and southern China (BirdLife International 2016). Due to its large body size (average body weight: $3.8-5.0 \mathrm{~kg}$, maximum body weight: $7.0 \mathrm{~kg}$ ) and magnificent plumage, (especially the trains of males that can be more than $2 \mathrm{~m}$ long), the bird has experienced great hunting pressure across its geographic range (McGowan et al. 1999; BirdLife International 2016). One of the three subspecies $P$. m. muticus only exists in Java and has disappeared from peninsular Malaysia and Thailand. The subspecies $P$. $m$. spicifer, distributes from northwest to central and southern Myanmar, to SW Thailand, may be extinct in NE India and Bangladesh. The subspecies of P. m. imperator has also experienced sharp population declines throughout its range from east Myanmar to Thailand, Laos, Cambodia, Vietnam and Yunnan Province in China (McGowan et al. 1999; BirdLife International 2016). Due to the deteriorating conservation status of Green Peafowl, it was uplisted from Vulnerable to Endangered on the International Union for the Conservation of Nature (IUCN) Red List in 2009 (BirdLife International 2016).

With 35\% (55 species) of the 159 pheasant species, China has the highest diversity of pheasants in the world (Zheng 2015), and 12 species are considered as threatened on the IUCN Red List (BirdLife International 2016). Although substantial progress has been achieved in pheasant studies and conservation in China, most of these studies have not fully considered basic demography information (Zheng 2015), which is an important reference basis for assessing a species status and establishing conservation plans. According to the Red List of China's Biodiversity that was officially released in 2015, the Green Peafowl was classified as a critically endangered species due to the rapid decline of its population, restricted distribution and continued habitat loss (MEP and CAS 2015). The historical range of the bird in China once extended to northern, central and southern China, including Hubei, Hunan, Guangdong, Guangxi, Yunnan and Tibet (Wen and He 1981; Yin and Liu 1993). However, their distribution range has concentrated to central, western and southern Yunnan, SW China, and the estimated population was 800-1100 individuals during 1991-1996 (Wen et al. 1995; Yang et al. 1997). Studies on the population and distribution of this endangered species in China were mainly completed in the 1990s (Wen et al. 1995; Xu 1995; Yang et al. 1997; Luo and Dong 1998;), and field surveys have not been conducted since then (Han et al. 2009). The absence of information on the species over the past 20 years has hindered the conservation planning, making species assessment challenging both in China and around the world. In this study, by combining historical reports and field studies, we are planning to: (1) figure out distribution range shifts over the past three decades; (2) understand population dynamic including general tendency of population number and structure (e.g. flock size); then (3) determine and assess the threats faced by the bird across its distribution ranges in China. At the end, we hope our findings could benefit future conservations and studies of Green Peafowl in China through outlining explicit research objectives and conservation measurements.

\section{Methods}

\section{Data collection}

By reviewing the literature, we summarized the past distribution and status of the birds before the field work. Then field surveys were conducted throughout the historical ranges of Green Peafowl distribution in China, including 11 districts of Yunnan Province (Wen et al. 1995; Yang et al. 1997) and 2 districts of Tibet (Yin and Liu 1993) during 2014-2017. Due to the large body size, distinctive plumage and importance in traditional Chinese culture, the Green Peafowl is well-known by Chinese people and unlikely to be confused with any other species. Thus, an interview survey, which was also adopted in former studies of 1990s (Wen et al. 1995; Yang et al. 1997), is likely to be a reliable and effective method to survey the population and distribution of the species across the large study area (covering $394,000 \mathrm{~km}^{2}$ in Yunnan Province and $50,600 \mathrm{~km}^{2}$ in Tibet). Therefore, we repeated the studies conducted in the 1990s and used the interview method to determine the present distribution of Green Peafowl. And also rough data of bird population number and flock size could be obtained from experienced interviewees (Wen et al. 1995). So, for the interviews, we focused only on staff from the local forestry bureaus, the forest rangers, elder males and hunters who had more experience and knowledge of wildlife, but not the public. To avoid disturbance by the interviewers, we recorded the conversations with the interviewees and extracted the information of interest instead of distributing standard questionnaires or providing potential options for each question. Questions regarding the year, location, population number, flock size, habitat and potential threats were asked to each interviewee. We set forth our investigation purpose to every interviewee before the interviewing. The interview would be continued only if the interviewee would like to answer our questions and was recognized as a valid independent sampling (interview), otherwise the conversion was 
terminated. Totally, we collected 173 valid samplings (4 interviewees refused our request) from 177 interviewees including 150 males and 27 females. Although interview survey are not standard method in population estimation and may lead unreliable results, it still give us an opportunity in exploring population changes with 1990s by using the same method. Moreover, it seems to be an effective method to collect species information across the vast areas.

Line transects methods were also used to supplement the interview surveys. Due to significant difference in climate, topography, habitat, accessibility, and even different minorities and cultures across our study area, it made systematic line transects survey impossible; and the survey efforts changed a lot. We took the line transects survey at the locations where the Green Peafowl was recorded in former literatures and according to our interviewing results. Green Peafowl habituates in tropical and subtropical natural vegetation below $2000 \mathrm{~m}$ altitude, such as deciduous broad-leaved forests, evergreen forests, deciduous-coniferous forests, savanna shrublands and grasslands, and also farmlands (Zheng 2015; Nuttal et al. 2017; Sukumal et al. 2017). So, we set the line transects in those habitats. Totally, we set 190 line transects covering $784 \mathrm{~km}$ in 24 counties of Yunnan and 19 line transects covering $81 \mathrm{~km}$ in Tibet. Most of the line transects were checked once by $2-4$ observers during 2014-2017. We confirmed the presence of Green Peafowl if any evidence, including birds, calls, body remains, feathers, and footprints were discovered along the line transect. The footprints could be found at river beach. By measuring four Green Peafowl specimens kept in Kunming Institute of Zoology, Chinese Academy of Sciences, we determined the length of the middle toes of the bird as $93.13 \pm 8.32 \mathrm{~mm}(n=4$; range: $80.44-102.63 \mathrm{~mm})$. So, we considered the typical bird footprints (three toes forwards and one toe backwards for pheasants) discovered along the river bank, with at least $90 \mathrm{~mm}$ middle toe in length as footprints of Green Peafowl.

To understand the impact extent (at the administrative county level) of specific threats on the Green Peafowl in China, we determined the threats by literature reviewing and discussing with interviewees. Due to the extremely low detection rate of the bird along the line transects, no threatening information was collected with line transect method.

\section{Data processing}

This study was divided into four periods: pre-1991, 1991-2000, 2001-2010 and 2011-2017. We considered the data of 2011-2017 as the present status of the bird. Only distribution data could be detected before 2010 from the literature mentioned above and Han et al.
(2009). To determine the distribution of Green Peafowl in this study, we counted the number of administrative counties and towns where the bird occurred in the past and at present. The past distribution were determined from published documents mentioned above, while present distribution were confirmed by interviewing and line transect survey.

For the population number and flock size, we could only collected rough data, mainly numerical ranges rather than single value, from interviewees both in the literatures and in this study. So, the minimum and maximum of the numerical ranges of both population number and flock size were calculated separately. From the literatures, both interviewed population numbers (derived from interviewees) and estimated population numbers (authors did not present detailed population estimating methods) could be obtained; and both were listed in the Additional file 1: Table S1. However, we only presented interviewed population number at present in our study for reducing arbitrariness of estimated population number from investigators. Because any forms of recalculation or estimation based on low reliability interviewed data could result bigger deviation. We did not implement population abundance or density estimates according to our line transects data due to the extremely low bird detection (Buckland et al. 2001); and only counts of the birds, calls, body remains, feathers or footprints were presented.

Previous studies have indicated that threats can be divided into three categories, including habitat loss/ degradation (e.g., habitat conversion, mining, hydropower and road construction), hunting (e.g., poisoning, poaching and egg collection) and human disturbance (e.g., mushroom picking, rosin harvesting, sand panning and herding) (Zheng 2015; Bird Life International 2016). However, these categories are too general to define the specific effects on Green Peafowl populations. In this study, we take the following four major threats into consideration, habitat conversion (from primary forest and traditional crops e.g. grains and beans to economic plantation including tea, coffee and fruits), poisoning, poaching (killing, chick capturing or egg collecting) and human disturbance (see the front part of this paragraph for details). Because a debate, surrounding a hydropower construction project along the Red River and Green Peafowl conservation in that area, occurred in China in 2017. We listed hydropower construction as a separate threatening factor leading to vital habitat loss. Thus, a total of five threats were considered in this study. Then, we assessed threats facing the bird at county level crossing its historical ranges in China. Threats affecting the Green Peafowl were obtained from literatures and interviews as mentioned above. 


\section{Results}

Present and historical distributions

In sum, Green Peafowl were recorded in 52 counties of 11 districts in Yunnan and 2 counties of one district in Tibet during the past 30 years in China (Table 1; Fig. 1). We found dramatic distribution range shrink in the past 20 years, from 127 towns and 34 counties of 11 districts in the period of 1991-2000, to 33 towns 22 counties of 8 districts at present in Yunnan Province. Green Peafowl were not recorded in Motuo and Chayu, Tibet in this study.

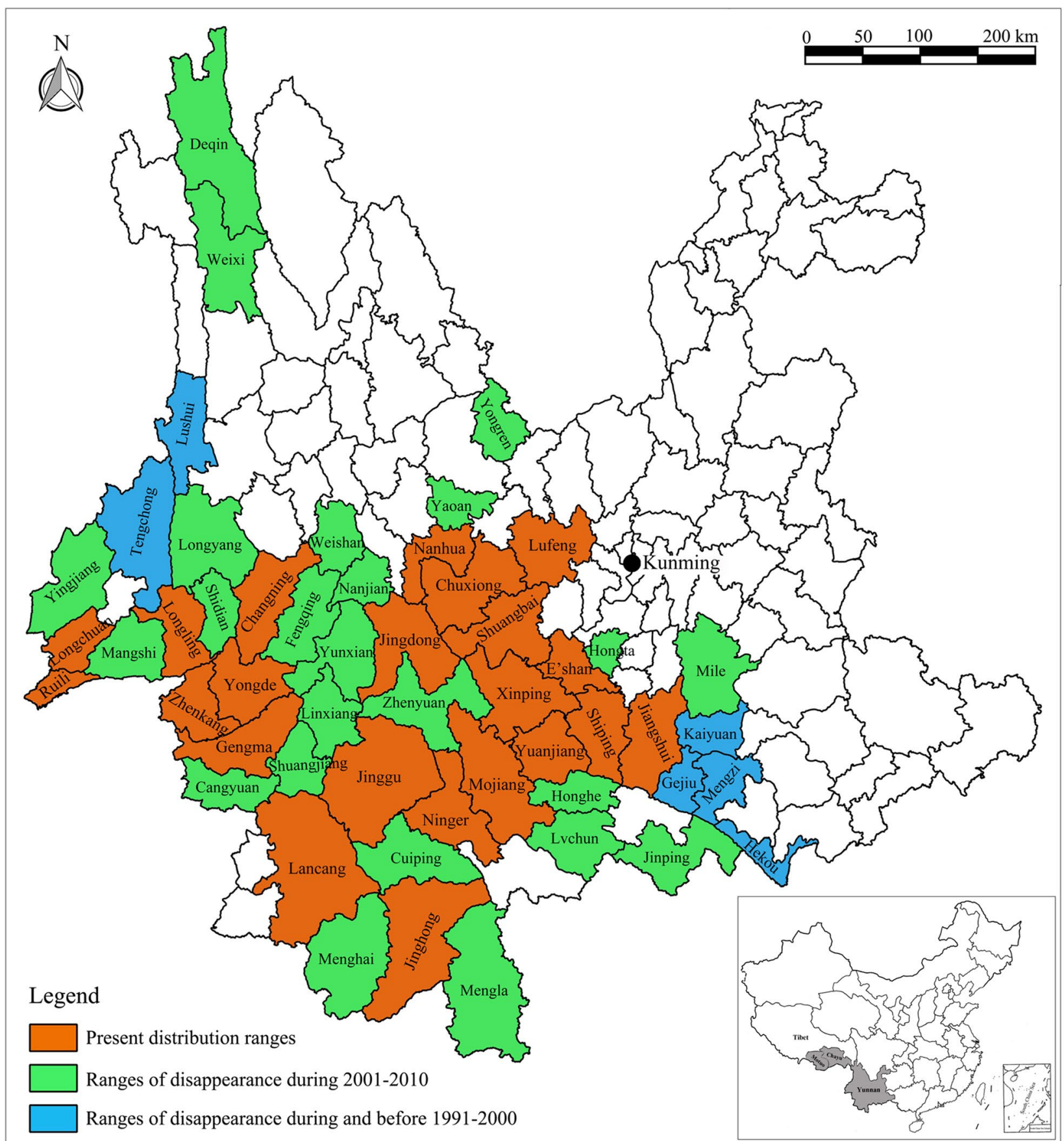

Fig. 1 Past and present distribution ranges (coloured areas) of the endangered Green Peafowl in Yunnan, SW China. Grey areas of the map in the lower right corner indicates our study area in China 
All those 8 districts with the occurrence of Green Peafowls, including Chuxiong, Yuxi, Pu'er (formerly Simao), Lincang, Baoshan, Dehong, Honghe and Xishuangbanna, were located in the central, western and southern Yunnan. We did not collect any strong evidence supporting the presence of Green Peafowl in the Dali, Diqing and Nujiang districts in Yunnan (Table 2). We also discovered Green Peafowls in Yuanjiang and E'shan counties, central Yunnan, which were not recorded before (Table 1).

\section{Present and historical populations}

In this study, we found sharp population decline compared with 20 years ago. There were $>585-674$ birds were recorded during 1991-2000 across 34 counties in Yunnan province, while only $\geq 183-240$ birds were recorded in this study with the same interviewing method in 48 counties. For the 34 counties investigated during 1991-2000, populations of Green Peafowl in 30 counties showed a downward trend. We found a slight increase of population in the adjacent two counties of Shuangbai and Xinping in central Yunnan, where more than $60 \%$ (63.93-69.17\%) of the total populations (according to the interviewing results) in Yunnan distributed.

Table 1 Number of counties and towns where Green Peafowl has been recorded in Yunnan, SW China showing changes over the last $\mathbf{3 0}$ years in 10-year time periods

\begin{tabular}{llll}
\hline Time period & \multicolumn{2}{l}{$\begin{array}{l}\text { Number of locations } \\
\text { with presence }\end{array}$} & $\begin{array}{l}\text { Total } \\
\text { counties } \\
\text { recorded }\end{array}$ \\
\cline { 2 - 3 } & Counties & Towns & \\
\hline Pre-2000 & 34 & 120 & 41 \\
$2001-2010$ & 40 & - & 50 \\
$2011-2017$ & 22 & 33 & 52 \\
\hline
\end{tabular}

We recorded one pair and 6 calls along the line transects located in Konglonghe nature reserve, Shuangbai county. And 12 footprints were also detected along the river beach of Xiaojiang, one branch of Shiyangjiang River (also known as the upstream of the Red River) in this reserve. One male bird was sighted in Zhelong town, Xinping county. One residual body was collected at Jiangzhongshan, Longling county of Baoshan district. We did not find any evidence indicating the presence of Green Peafowl in the other line transects covering nearly $800 \mathrm{~km}$ in Yunnan and Tibet, indicating extremely low encounter rate (Table 2).

\section{Present and historical flock sizes}

We found a steady decrease in the average flock size over the past 30 years (Table 3 ). The average flock size declined distinctively from 8-20 individuals before 2000 to less than 5 birds per flock since then; while the maximum flock size remained stable. And in our study, large flocks of 18-27 birds was discovered with interview method in Shuangbai and Xinping counties.

\section{Threats}

For the 54 historical distribution counties of Green Peafowl in China (52 in Yunnan and 2 in Tibet), we determined threats affecting the bird in 37 counties by both literature reviewing and interviewing. Nearly all the populations (36 counties) were disturbed by human activities including mushroom picking, rosin harvesting, sand panning and herding in their natural habitats. Habitat conversion from primary forests and traditional croplands to economic plantations, which leading to habitat loss, threatened populations in 27 counties. We found that the Green Peafowl faced poaching in 31 counties and poisoning in 10 counties. Compared with the other four types

Table 2 Number of the endangered Green Peafowl detected along the line transects in China during 2014-2017

\begin{tabular}{|c|c|c|c|c|c|c|c|c|}
\hline District & Date (yyyy.mm) & $\begin{array}{l}\text { Number } \\
\text { of transects }\end{array}$ & $\begin{array}{l}\text { Length } \\
\text { of transects } \\
(\mathrm{km})\end{array}$ & Altitude (m) & Birds & Carcasses & Footprints & Calls \\
\hline Chuxiong, Yunnan & $2014.04,2016.04 / 05,2017.04 / 05$ & 5 & 16 & $647-1803$ & 2 & 0 & 12 & 6 \\
\hline Yuxi, Yunnan & 2014.01/07/08/12, 2015.01 & 31 & 205 & $340-2159$ & 1 & 0 & 0 & 0 \\
\hline Lincang, Yunnan & $2014.09,2015.05$ & 34 & 141 & 485-1994 & 0 & 0 & 0 & 0 \\
\hline Dehong, Yunnan & 2014.04 & 1 & 17 & $1381-1909$ & 0 & 0 & 0 & 0 \\
\hline Baoshan, Yunnan & 2014.04 & 1 & 10 & $940-1216$ & 0 & 1 & 0 & 0 \\
\hline Xishuanbanna, Yunnan & 2014.08 & 1 & 4 & $1581-1670$ & 0 & 0 & 0 & 0 \\
\hline Honghe, Yunnan & $2014.04 / 08,2015.11 / 12$ & 114 & 379 & 532-1998 & 0 & 0 & 0 & 0 \\
\hline Nujiang, Yunnan & 2015.09 & 3 & 11 & $1161-1733$ & 0 & 0 & 0 & 0 \\
\hline Diqing, Yunnan & - & - & - & - & - & - & - & - \\
\hline Linzhi, Tibet & 2016.04 & 19 & 81 & $723-2043$ & 0 & 0 & 0 & 0 \\
\hline Total & & 209 & 865 & & 4 & 1 & 12 & 6 \\
\hline
\end{tabular}


Table 3 Changes in flock size (birds per flock) of the endangered Green Peafowl in Yunnan, China across historical periods determined by interviewing and literature reviewing

\begin{tabular}{lllll}
\hline & $\mathbf{2 0 1 1 - 2 0 1 7}$ & $\mathbf{2 0 0 1 - 2 0 1 0}$ & $\mathbf{1 9 9 1 - 2 0 0 0}$ & Pre-1991 \\
\hline Average flock size (birds/flock) & $3.36-4.84$ & $3.59-5.5$ & $8.58-10.42$ & $8.5-20$ \\
Range of flock size & $1-27$ & $1-20$ & $1-30$ & $7-30$ \\
Sample size $(n)$ & 25 & 22 & 12 & 2 \\
\hline
\end{tabular}

Sample size $(n)$ indicates the number of interviewees or data sets collected from literatures

of threats, hydropower construction affected the survival of the birds at regional level (4 counties) through flooding suitable habitats in the valley. At the same time, the endangered Green Peafowl also faced pressures from several of these five threatening factors in many distribution ranges.

\section{Discussion}

Although rigorous population estimate methods (e.g., distance sampling) are preferred by conservationists, these methods have many limitations and challenges. Extremely low encounter rates or visual detections limited the detection function and estimations of cluster sizes during the distance sampling analysis, which were documented in both our and former studies (Nuttal et al. 2017). It is also a large challenge for investigators that walk transects in tropical forest environments to ensure acceptable amounts of data (Nuttal et al. 2017). In consideration of these challenges and the limitations of rigorous distance sampling methods, other methods, e.g. line transects were used to determine the density of calling male Green Peafowl (calling birds per $\mathrm{km}^{2}$ ) during the breeding season in southcentral Vietnam and western Thailand (Sukumal et al. 2015, 2017) or transect call counting and concentrated counting methods, were used in East Java (Hernowo et al. 2011) and also point count method in Myanmar (Aung et al. 2013). While these methods could work properly at the regional scale, such as in a reserve or national park (mentioned above), they are not efficient enough at a broad scale as covered by our study. Therefore, we conducted a field survey using the interviewing method, which is an efficient method to understand the general status of well-known species (Li and Chan 2017). So we repeated population survey of Green Peafowl with the same interviewing method as conducted in the 1990s (Wen et al. 1995; Yang et al. 1997), to explore the status changes of the bird in China.

In this study, we figured out the population status of the endangered Green Peafowl over the past three decades in China at the global scale through the greatest survey efforts ever made and literature reviewing. Although interviewing method could not obtain robust population size, it is helpful in exploring relative population abundance at the global scale and understanding historical population changes. We confirmed the limited and concentrated distribution of the bird only in 8 administrative districts of Yunnan in China; and no bird was discovered in Tibet with both interviewing and line transect methods. We documented the presence of Green Peafowl in 22 of the 52 historical counties in Yunnan, and nearly $80 \%$ of the present population was distributed in the Chuxiong ( $\geq 108-158$ interviewed birds) and Yuxi ( 32-34 interviewed birds) districts in central Yunnan. The interview methods revealed that there were about 40-60 birds habituated in the Konglonghe nature reserve, Shuangbai county, Chuxiong district. While about 59 adults and sub-adults and 20 chicks were identified by camera trapping in the same area in 2016 (Dr. P. Shan, personal communication). According to our study, only very small populations were scattered in the western and southern areas of Yunnan near the study boundary, such as Longba town in Longchuan county of Dehong Prefecture, Nuofu town in Lancang county of Pu'er and Menglong town in Jinghong of Xishuangbanna Prefecture. Compared with investigations conducted 20 years ago, more than $56 \%$ of the distributed counties and $80 \%$ of the distributed towns disappeared. The same distribution shrink also occurred in other Southeast Asian regions, including Java (Hernowo et al. 2011), Laos (Vongkhamheng 2015), Myanmar (Aung et al. 2013) and Vietnam (Sukumal et al. 2015).

Though we found widespread population declines of the Green Peafowl across most of their ranges in Yunnan, it is not the case for populations in Shuangbai county of Chuxiong district and Xinping county of Yuxi district, central Yunnan. We were pleased to find that the population increased in Shuangbai (79 interviewed birds in 1990s vs. 98-145 interviewed birds at present); and populations kept stable and slightly growing in Xinping (17-18 birds in the 1990 s vs. $19-21$ at present). This may also due to survey effort difference. Besides, we discovered large Green Peafowl flocks of 18-27 adult birds in this area with interviewing method; and birds, calls and footprints were detected along the line transects set in the Konglonghe Nature Reserve locating in the border of Shuangbai and Xinping county. All these finds indicated that this area may hold the biggest population and highest density of Green Peafowl in China, needs through population survey and habitat assessment. We believe 
that the vast undestroyed vegetation (including monsoon forest, savanna shrub and grass), scarce human disturbance and daily patrolling and monitoring contributed to the population rise in this area. Population increases were found in some of the national parks in Southeast Asia. The Java Green Peafowl in Alas Purwo National Park, East Java increased by $86 \%$ in 8 years compared with the observations in 1998 (Hernowo et al. 2011). In south and central Cat Tien National Park in southcentral Vietnam, the density of Green Peafowl was estimated to be higher than 15 years ago (Sukumal et al. 2015). In addition, in the Huai Kha Khaeng Wildlife Sanctuary of western Thailand, population recovery was also documented (Sukumal et al. 2017). These results suggest that given adequate protection, Green Peafowl populations can recover both in China and Southeast Asia.

Meanwhile, we detected decrease of average flock size of the bird from the 1990s to present in this study, but the range of flock size remained stable. This result indicates that only the frequency of sighting large flocks of Green Peafowl reduced. It is easy to imagine that the decline in the bird population led to decreases of the average flock size and population density, or lower encounter rates (Nuttal et al. 2017; Sukumal et al. 2017). But big flocks of 18-27 birds still could still be found in the field, which inspires confidence of population recovery of the endangered Green Peafowl.

During our conversations with local people and in the documents, we found that poisoning caused massive Green Peafowl deaths in the last century because the bird would sometimes forage on crops. A large proportion of the Green Peafowl was poisoned from 1960-1970 in Xishuangbanna District, southern Yunnan (Luo and Dong 1998). Xu (1995) reported that 19 Green Peafowls were poisoned during 1990-1994 in Chuxiong District, central Yunnan. Moreover, poisoning cases still occasionally happened because of the usage of pesticide-coated seeds (mainly hexachlorocyclohexane was used before 1980 s and was replaced by phoxim after that) in farming. A total of 18 Green Peafowls were killed by poisoned seeds in Jiangzhongshan, Baoshan, western Yunnan during 2002-2004 (Ai 2006). In our study, local farmers of Pu'er, Dali and Lincang also said that pesticide-soaked soybean were trapped to kill Green Peafowl and prevent foraging on crops, and the birds died in flocks. Except for poisoning-induced death, massive bird loss was also caused by poaching, including bird killing, bird capturing and egg collecting. As Xu (1995) documented, more than $1 / 3$ of the 280 Green Peafowls were hunted (including 30 killed birds, 23 captured birds, 19 poisoned birds and 21 eggs) in Chuxiong District in the 1990s. A literature review revealed that approximately 120 individuals of Green Peafowl were killed by humans in Chuxiong,
Baoshan, Dehong, Lincang and Pu'er (formerly Simao) from 1988-1995 (Xu 1995; Wen et al. 1995; Yang et al. 1997). We infer that hunting, including poaching, poisoning, bird capturing and egg collecting, were the main reasons for the sharp population declines of Green Peafowl in China in the last century (Wen et al. 1995; McGowan et al. 1999).

Our results also indicated that poaching existed in the past and at present and is a widespread threat to Green Peafowl in more than $80 \%$ of their distribution counties. Yunnan has the highest diversity of national minorities, and hunting is the traditional culture of many minorities in the province. Therefore, although wildlife conservation laws were first promulgated in 1988, hunting still occurred, especially in the minority autonomy areas of western and southern Yunnan. These could also explain why only rather small populations remained in those areas as documented by our results. Large-scale and systematic studies have also documented that hunting is a major driver of biodiversity loss in tropical mammal and bird populations (Benítez-López et al. 2017). In addition, due to the large body size and hunting vulnerability of pheasants (like the Green Peafowl), the Phasianidae has become one of the six most threatened families in China (Wang et al. 2017).

In our study, we found that habitat conversion is another widespread threat to Green Peafowl, leading to numerous habitat losses. Vast natural habitats from the west to south of Yunnan were converted to agricultural and commercial plantations, e.g., sugarcane, rubber tree, tea, fruit and coffee. In western Yunnan ranging from Nujiang, to Baoshan, Dehong and Lincang, the previous natural vegetation below $1600 \mathrm{~m}$, such as savanna shrub and grass vegetation that was utilized by Green Peafowl, was removed and commercial crops such as tea, fruit, coffee and sugarcane were planted around 1990 (Luo and Dong 1998). In Xishuangbanna of south Yunnan, the primary forest of Simao Pine (Pinus kesiya var. langbianensis), natural habitats of Green Peafowl, decreased from $60 \%$ before 1950 to $23 \%$ in the 1990 s in coverage (Luo and Dong 1998). All these primary forests were replaced by rubber plantation gardens since 1956 (Luo and Dong 1998; Ziegler et al. 2009); and only approximately 19-25 birds left after 1995 (Luo and Dong 1998). What's worse, habitat conversion caused not only specific population declines of endangered species (e.g. the Green Peafowl), but also biodiversity loss of the whole ecosystem (Gaston et al. 2003; Li et al. 2006; Zhang et al. 2017); and the progress of habitat conversion is still going on.

During our field survey in Qinghua town in Weishan county of Dali district, western Yunnan, where the first reserve was established for protecting Green Peafowl in Yunnan, we found that the habitats were converted 
from evergreen and deciduous broadleaved forests to traditional cultivated crops (e.g., soybean and corn), and Green Peafowls were observed foraging in those agricultural areas adjacent to forest. But the traditional planted farmlands were then converted to tea garden, which is no longer used by the birds. Moreover, a large hydropower project was constructed in 2001 on the Lancang-Meikong River, and the flooding area covered the valleys of Qinghua where Green Peafowl should be distributed. In this study, unfortunately, we did not find any signs indicating the presence of Green Peafowl in this area, and the following camera trapping did not capture any pictures of the bird (Dr. X. Luo, personal communication).

As a cryptic pheasant species, Green Peafowls usually prefer habitat far away from human settlements (Nuttal et al. 2017; Sukumal et al. 2017). Human disturbances to Green Peafowl include mining, rosin harvesting, sand panning and herding in the past and mushroom picking, herding and mining at present. Human disturbances have effects on Green Peafowl distribution by reducing their potential available habitat (Liu et al. 2008; Saridnirun et al. 2016), but do not result in direct bird death. So human disturbance seems having limited impacts on Green Peafowl though this happened in nearly all of the ranges of the bird, and birds could be observed in habitats closed to human habitation in Myanmar (Aung et al. 2013).

Based on our studies, we outline suggestions on conservation, management and research in the future as follows:

1. High priority for conservation and research should focus on the area of Shuangbai and the adjacent Xinping county, central Yunnan, where the largest population of the Green Peafowl distributed in China. Rigorous population (including line transect-based distance sampling and camera trapping methods), distribution and habitat investigations, should be conducted in this area before taking next-step conservation measurements.

2. In consideration of inaccessibility of tropical and subtropical forest the Green Peafowl habituated, species distribution models (SDM) based potential distribution predicting could guide field population survey and help clarify conservation gaps.

3. Both micro and macro habitat selection studies, which could help determine the ecological requirements of the species and ensure effective conservation management, are important and welcomed.

4. Poaching should be strictly prohibited, and any forms of habitat conversion should be limited.

\section{Conclusions}

In this study, we conducted a thorough field survey and comprehensive literature review of Green Peafowl across all historical distribution ranges of the species in China. We depicted the population and distribution changes of the bird over the past three decades (1990s-2017). Our results indicated that Green Peafowls occurred in 52 counties in Yunnan Province and 2 counties in Tibet, China. Dramatic population declines and distribution concentrations occurred over the past 30 years. There were $35 \%$ of former counties and $74 \%$ of former towns disappeared in 20 years. The remaining Green Peafowls were distributed in 33 towns, 22 counties and 8 districts of Yunnan, SW China. Based on the interview data, only 183-240 birds were recorded; and actual population definitely was underestimated. More than $3 / 4$ of the population was located in Chuxiong and Yuxi district, central Yunnan. We concluded that hunting (poaching and poisoning) drove the population declines in the last century. Habitat conversion and poaching threatened the survival of the bird in the past and present.

\section{Additional file}

Additional file 1. Table S1: Historical and present status and distribution of endangered green peafowl in Yunnan, SW China (1990s-2017).

\section{Authors' contributions}

DK, FW and XY conceived, designed and directed the experiments and coordinated this study. DK wrote and revised the manuscript. DK, FW, PS, JG, DY and WL performed the field work. All authors read and approved the final manuscript.

\section{Author details \\ ${ }^{1}$ Key Laboratory of Special Biological Resource Development and Utilization of Universities in Yunnan Province, Kunming University, Kunming 650214, China. ${ }^{2}$ Bird Group, Kunming Institute of Zoology, Chinese Academy of Sci- ences, Kunming 650223, China. ${ }^{3}$ Kunming Survey and Design Institute of State Forestry Administration, Kunming 650216, China.}

\section{Acknowledgements}

We appreciate the permission and field assistance of these governmental agencies and staff, the Forestry Departments of Yunnan Province and every administrative district mentioned above, Yunnan Environmental Protection Department, Konglonghe Nature Reserve, Ailaoshan National Nature Reserve, Wuliangshan National Nature Reserve, Yuanjiang National Nature Reserve, Xishuangbanna National Nature Reserve, Daxueshan National Nature Reserve, Nangunhe National Nature Reserve, Tongbiguan Provincial Nature Reserve, Xiaoheishan Provincial Nature Reserve, Qinghua Provincial Nature Reserve, Zhangmuqing Provincial Nature Reserve, Xigui Forestry Farm, Ruili Institute of Tropical Crops, and Moli Tropical Rainforest Scenic Area. Many thanks to our interviewees who provided valuable information on Green Peafowl. We thank our colleague Guangyi Lu for map preparation. We are grateful to the three anonymous reviewers whose valuable comments improved our manuscript a lot.

\section{Competing interests}

The authors declare that they have no competing interests. The funders had no role in study design, data collection and analysis, decision to publish, or preparation of the manuscript. 


\section{Consent for publication}

Not applicable.

\section{Ethical approval}

The investigations comply with the current laws of China in which they were performed.

\section{Funding}

We appreciated the financial supports from the Biodiversity Conservation Fund from Yunnan Environmental Protection Department and Special Funds for Green Peafowl Investigation from State Forestry Administration of the People's Republic of China. This work was further supported by the Key Laboratory of Special Biological Resource Development and Utilization of Universities in Yunnan Province.

Received: 10 October 2017 Accepted: 15 May 2018

Published online: 23 May 2018

\section{References}

Ai HS. Pheasant diversity and conservation in the Mt. Gaoligongshan region. Zool Res. 2006;27(4):427-32 (in Chinese).

Aung TDW, Win L, Moses S. The preliminary population assessment of green peafowl in central Myanmar. 2013. https://www.rufford.org/files/12815 -1\%20Preliminary\%20Population\%20Assessments\%20Report.pdf. Accessed 10 Feb 2018.

Benítez-López A, Alkemade R, Schipper AM, Ingram DJ, Verweij PA, Eikelboom JAJ, Huijbregts MAJ. The impact of hunting on tropical mammal and bird populations. Science. 2017;356:180-3.

BirdLife International. Pavo muticus. The IUCN red list of threatened species 2016. 2016

Buckland ST, Anderson DR, Burnham KP, Laake JL, Borchers DL, Tomas L. Introduction to distance sampling: estimating abundance of populations. Oxford, UK: Oxford University Press; 2001.

Gaston KJ, Blackburn TM, Goldewijk KK. Habitat conversion and global avian biodiversity loss. Ecol Lett. 2003;270:1293-300.

Han LX, Liu YQ, Han B. The status and distribution of green peafowl Pavo muticus in Yunnan Province, China. Int J Galliformes Conserv. 2009;1:29-31.

Hernowo JB, Alikodra HS, Mardiastuti A, Kusmana C. Population analysis of the javan green peafowl (Pavo muticus muticus Linnaeus 1758) in Baluran and Alas Purwo National Parks, East Java. Biodiversitas. 2011;12:99-106.

Li F, Chan BPL. Past and present: the status and distribution of otters (Carnivora: Lutrinae) in China. Oryx. 2017. https://doi.org/10.1017/S0030 605317000400.

Li HM, Aide M, Ma YX, Liu WJ, Cao M. Demand for rubber is causing the loss of high diversity rain forest in SW China. In: Hawksworth DL, Bull AT, editors. Plant conservation and biodiverstiy. Dordrecht: Springer; 2006. p. 157-71.

Liu Z, Zhou W, Zhang RG, Xie YC, Huang QW, Wen YY. Foraging sites selection of green peafowl (Pavo muticus imperator) in different seasons in
Shiyangjiang Valley of upper Yuanjiang drainage, Yunnan. Biodivers Sci. 2008;16:539-46 (in Chinese)

Luo AD, Dong YH. Investigation on the current status of distribution and population of the Green Peafowl in Xishuangbanna. Chin J Ecol. 1998;17(5):6-10 (in Chinese).

McGowan PJK, Duckworth JW, Xianji W, Van Balen B, Yang XJ, Khan KM, Yatim $\mathrm{SH}$, Thanga L, Setiwan I, Kaul R. A review of the status of the Green Peafowl Pavo muticus and recommendations for future action. Bird Conserv Int. 1999:9:331-48.

MEP (Ministry of Environment Protection of the People's Republic of China) and CAS (The Chinese Academy of Sciences). Redlist of China's biodiversity—birds. 2015. http://www.zhb.gov.cn/gkml/hbb/bgg/201505/W0201 50526581939212392.pdf. Accessed 12 Jan 2018.

Nuttal M, Nut M, Ung V, O'Kelly H. Abundance estimates for the endangered Green Peafowl Pavo muticus in Cambodia: identification of a globally important site for conservation. Bird Conserv Int. 2017;27:127-39.

Saridnirun G, Dumrongrojwatthana P, Meckvichai W, Nispa S, Khuntathongsakudi K. Seasonal distribution an habitat use of green peafowl Pavo muticus Linnaues, 1766, in Nam Whean Forest Protection Unit, Northern Thailand. Walailak J Sci Tech. 2016:13:729-44

Sukumal N, Dowell SD, Savini T. Micro-habitat selection and population recovery of the Endangered Green Peafowl Pavo muticus in western Thailand: implications for conservation guidance. Bird Conserv Int. 2017;27:414-30.

Sukumal N, McGowan PJK, Savini T. Change in status of green peafowl Pavo muticus (Family Phasianidae) in Southcentral Vietnam: a comparison over 15 years. Glob Ecol Conserv. 2015;3:11-9.

Vongkhamheng. Phou Khao Khouay National Protected Area: a field survey of green peafowl (Pavo Muticus). In: Effective implementation of payments for environmental services in Laos PDR. Research Report No. 7. 2015. p. $1-13$.

Wang YP, Si XF, Bennett PM, Chen CW, Zeng D, Zhao YH, Wu YR, Ding P. Ecological correlates of extinction risk in Chinese birds. Ecography. 2017:41:782-94.

Wen HR, He YH. Geographical distribution and changes of green peafowl in the historical periods in China. Histor Geogr. 1981;1:132-9.

Wen XJ, Yang XJ, Han LX, Yang L, Wang WM. Investigation on the current status of the distribution of green peafowl in China. Chin Biodivers. 1995:3:46-51.

$\mathrm{Xu} \mathrm{H}$. The distribution status and protection measure of Pavamuticus in Chuxiong District. Forest Sci Yunnan. 1995;3:48-52 (in Chinese)

Yang XJ, Wen XJ, Yang L. The range of green peafowl Pavo muticus imperator in Southeast and Northwest Yunnan Province, China. Zool Res. 1997;18(12):18

Yin BG, Liu WL. Wildlife and its conservation in Tibet. Beijing, China: Forestry Publishing House; 1993. p. 136-7.

Zhang MX, Charlotte C, Quan RC. Natural forest at landscape scale is most important for bird conservation in rubber plantation. Biol Conserv. 2017;210:243-52.

Zheng GM. Pheasants in China. Beijing: Higher Education Press; 2015.

Ziegler AD, Fox JM, Xu J. The rubber juggernaut. Science. 2009;324:1024-5.
Ready to submit your research? Choose BMC and benefit from:

- fast, convenient online submission

- thorough peer review by experienced researchers in your field

- rapid publication on acceptance

- support for research data, including large and complex data types

- gold Open Access which fosters wider collaboration and increased citations

- maximum visibility for your research: over 100M website views per year

At BMC, research is always in progress.

Learn more biomedcentral.com/submissions 